http://jmscr.igmpublication.org/home/

ISSN (e)-2347-176x ISSN (p) 2455-0450

crossref DOI: https://dx.doi.org/10.18535/jmscr/v7i10.128

Journal Of Medical Science And Clinical Research

\title{
How Much to Expect in ACL-Reconstruction, MCL Repair and Meniscus Rasping - Two years follow up with Specific Evidence Based Exercises
}

Authors

\section{Dr S.S.Subramanian, M.P.T (Orthopaedics), M.S (Education), M. Phil (Education), Ph.D (Physiotherapy) ${ }^{1}$, Dr S. Beula Subaranjani., BDS., M.sc (Anatomy) ${ }^{2}$}

${ }^{1}$ The Principal, Sree Balaji College Of physiotherapy, Chennai - 100. Affiliated To (Bharath) University, BIHER, Chennai - 73.

${ }^{2}$ Asst. Professor in Anatomy, Sree Balaji College Of physiotherapy, Chennai - 100, Affiliated To (Bharath) University, BIHER, Chennai - 73.

\begin{abstract}
Road traffic accidents are commonly recorded in developing countries. Rehabilitation after knee surgeries needs to be established with patient centric approach. Aims \& Objectives of this research was to analyse the efficacy of protocol based exercises plus problem based exercises on a subject post ACL reconstruction, medial meniscus rasping and medical ligament repair.

Materials \& Methodology: She was treated during the period from (3rd Post-Operative Day) 08.07.2017 till 30.9.2019. A part from protocol based exercises, core strengthening and exercises to both upper extremities and contra lateral leg were used. With weekly thrice frequency of 25-30 minutes / session.

Results: Pre and Post womac score and obesity has shown $P<.05$ and clinical prognosis were discussed with evidence.

Conclusion: Outcome of this study findings can be validated for application in rehabilitation of similar knee surgery subjects.

Keywords: $A C L-R-$ Anterior Cruciate Ligament - Rehabilitation, MCL - Medial Collateral Ligament, QOL-Quality of Life, CKC-Closed Kinematic Chain.
\end{abstract}

\section{Introduction}

Anterior Cruciate Ligament Reconstruction (ACL-R) are done with an aim to reconstruct the kinematics, prevent joint instability and prevent the development of osteoarthritis as frequently seen after ACL-R (Hertel et al 2005), full weight bearing without braces was not permitted for 6-8 weeks, but (shelbourne and Nitzetal 1990) have recorded an accelerated rehab program, allowed athletes to return to normal function and athletic activities sooner than patients in the conventional rehab program
Advancement in surgical techniques, graft fixation have enabled early weight bearing on the day of surgery with braces and crutches and this reduce petallo femoral pain and lower the incidence of anterior knee pain compared with non weight bearing. Rehabilitation of the ACL Reconstruction of the knee is extremely important to athletes for all functional outcome. This has made Rehab protocols to undergo drastic changes since 2000 Rehabilitation after ACL-R Plays a major role in the functional outcomes of the extremity (Paulos et al 1991) and Recent trends includes immediate 
muscle exercises, core exercises early functional activities, Proprioceptive and neuromuscular controls drills (Wilk et al 2003, Lephart et al 1997) complications post ACL-R includes higher rate of Osteo Arthritis of knee joint (Keggler et al 2008).

Superficial medial collateral ligament with proximal tibial attachment is important for valgus stability (Griffith et al 2009) and the distal tibial attachment for external rotational stability (wijidicks et al 2010). Grade III MCL lesions are 95\% associated With ACL and $78 \%$ with meniscal injuries (Grant et al 2012).

The meniscus functions in load bearing, load transmission, shock absorption, joint stability, lubrication and congruity (wirth et al 1996).Menisci may serve as Proprioceptive structures providing a feedback mechanism for joint position sense (karahan et al 2010). Injuries involving ACL or MCL both can displace menisci and medial menisci injury has been found to be higher than the lateral $89 \%$ versus $29 \%$ (Warren et al 1978). Meniscal injuries are most common indications for knee surgery (Howell et al 2002)as excision of menisci leads to degeneration of articular cartilage (Allen et al 1984) hence amount of menisci removed should be minimal, repaired or replaced (Packer and Rodeo 2009). As few follow-up are available on ACL, MCL, Meniscal surgically treated, this Research where selective subject specific exercises including core strengthening, Proprioceptive, exercises to both upper extremity, contralateral leg and their outcome on QOL with two years follow-up are presented and critically discussed with evidence .

\section{Background Information}

29 year old female, a dentist had a fall while driving two wheeler and developed instability with pain in right knee. She was subsequently treated at Chennai based hospital by arthroscopic procedure ACL was reconstructed using STG grafting, MCL repair and medial meniscus rasping were done under general anesthesia on 06.07.2017 was discharged 07.07.2017 with an advice to be on Non weight bearing and Above knee brace for 6 weeks.

Aims \& Objectives of this original research was to analyse the efficacy of protocol along with problem based exercises on clinical prognosis and functional outcome measures on a subject surgically treated for ACL, MCL and Meniscal injury.

\section{Materials, Methodology and clinical prognosis}

The subject was treated by the author from 08/07/2017 till 30/09/2019. The clinical prognosis and functional outcome were discussed with evidence

Table 1

\begin{tabular}{|c|c|c|c|}
\hline $\begin{array}{l}\text { Measurable parameters } \\
\text { physical condition prior to } \\
\text { therapy }\end{array}$ & $\begin{array}{l}\text { Her physical condition } \\
\text { as on } 08 / 07 / 17\end{array}$ & Methodology used & $\begin{array}{l}\text { Clinical Prognosis Her physical } \\
\text { condition as on } 30 / 09 / 19\end{array}$ \\
\hline Range of motion & $\begin{array}{l}0-10 \text { degree of active } \\
\text { knee flexion (right) }\end{array}$ & 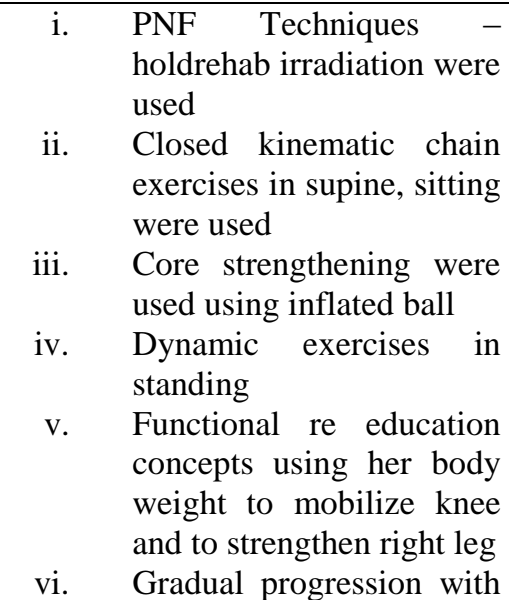 & $\begin{array}{llll}0 & -120 \quad \text { degree } & \text { of } & \text { Active } \\
\text { knee(right)flexion }\end{array}$ \\
\hline
\end{tabular}




\begin{tabular}{|c|c|c|c|c|}
\hline & & $\begin{array}{l}\text { vii. } \\
\text { viii. } \\
\text { ix. } \\
\text { x. }\end{array}$ & $\begin{array}{l}\text { exercises done to both } \\
\text { upper extremities/trunk } \\
\text { and both legs } \\
\text { Weight bearing was } \\
\text { progressed from } 4^{\text {th }} \text { week } \\
\text { to } 6^{\text {th }} \text { week she was } \\
\text { ambulant unaided } \\
\text { Exercises were done at an } \\
\text { intensity of } 60-70 \% \text { of } \\
\text { maximal heart rate } \\
\text { With weekly thrice } \\
\text { frequency ambulant } \\
\text { unaided with near normal } \\
\text { gait, drives two wheeler, } \\
\text { car, social activities } \\
\text {,cooking food, travelling, } \\
\text { confidence with floor } \\
\text { level activities were } \\
\text { Achieved with her womac } \\
\text { score at } 20 \text { from } 88 \text { prior } \\
\text { to therapy } \\
\text { She is getting treated once } \\
\text { a week from October } \\
2019 \text { for further follow-up } \\
\text { and adherence to } \\
\text { physiotherapy }\end{array}$ & \\
\hline $\begin{array}{l}\text { Pain } \\
\text { Visual Analogue Scale }\end{array}$ & $\begin{array}{l}\text { VAS } 8 / 10 \text { During } \\
\text { movements of right } \\
\text { leg }\end{array}$ & & & $\begin{array}{l}\text { VAS } 2 / 10 \\
\text { Pain increasing during mensural } \\
\text { cycle }\end{array}$ \\
\hline Waist circumference & $105 \mathrm{~cm}$ & & & $98 \mathrm{~cm}$ \\
\hline Gait & $\begin{array}{l}\text { Postoperative was for } \\
\text { reduction in obesity by } \\
6.6 \% \text { is note worthy } 4 \\
\text { weeks ambulant rim } \\
\text { non weight bearing } \\
\text { long knee brace and } \\
\text { walker }\end{array}$ & & & \\
\hline QOL & Womac score was 88 & & & Womac score was 20 \\
\hline
\end{tabular}

Table 2

Results of paired positive test on womac score and waist circumference

\begin{tabular}{|l|c|c|c|c|c|c|}
\hline \multirow{4}{*}{ Womac } & & Mean & SD & SE & t & P \\
\cline { 2 - 7 } & Pre & 88 & & & & \\
\cline { 2 - 7 } & Post & 20 & 29 & 17 & 4 & $<.05$ \\
\hline \multirow{2}{*}{ Waist circumference } & Pre & 105 & & & & \\
\cline { 2 - 7 } & Post & 98 & 3 & 1.70 & 4.12 & $<.05$ \\
\hline
\end{tabular}

\section{Discussion}

\section{ACL-R apart from accelerated protocol} with physiotherapy?

The conservative approaches that emphasized healing of the graft and stability of the knee (paulos et al 1991 \& Mallenpati et al 2015) have recorded that with numerous protocols exist for ACL-R, insisted on time focused approach with individualized than follow a rigid time line. However Author of this research have followed most recent ACL-R Protocol for specific mile stone from multicenter orthopedic outcomes network (Malone et al 2006)

a. Mallenpati et al 2015 have suggested that in acl- $\mathrm{R}$ rehabilitation ; prevent problems rather than treat them whenever possible ,Integrate open and closed kinematic chain exercises in rehabilitation and do not have patients discard assistive devices until they are able to activate quadriceps effectively and demonstrate a 
normal gait. Accelerated Protocols that have been proven to improve functional outcomes and to result in fewer complications. (wilk and Andrews 1991; shelbourne et al 1990).

b. A systematic rehab program should emphasize on the return to symmetrical motion aids in muscle strength and balance that must be achieved to provide dynamic stability (shelbourne et al 2006). This study was rehabilitated using above said research reports, hence an enhanced recovery as shown in table 2 of results.

\section{Complications post ACL-R and Role of physiotherapy}

11 years follow up with ACL injury subjects comparing conservative verses reconstructive treatment among 109 subjects in Switzerland, with similar physical activity among both, but reports risk of secondary meniscal tear was reduced among ACL-R, and better knee stability, but developed more osteoarthritis (OA) with $42 \%$ Where as among conservative subjects $24 \%$ incidence of (OA) was recorded. Meunier et al 2007 in a 15 years follow-up the status of the menisci was the most important predictor of developing osteoarthritis (Fithian et al 2005) in 6.6 years follow-up among 209 patients that reconstruction cannot prevent the occurrence of degeneration and their study included with and without meniscal lesions (MC Daniel and Dameron 1980) recorded that ACL rupture occurs along with Meniscal Lesion at $70 \%$. In two years regular follow-up this study subject has not developed any complications, but continued further duration may reveal prognosis.

\section{Is there a role for core strengthening among ACL-R?}

Core exercises should be made as an integral part of ACL R Rehab as proximal stability leads to distal mobility for maximizing functional improvements (shi.et al 2012). Panchal and Bedekaretal2015 have among 60 ACL-R of both sex between 20-40 years have in a four week period recorded core exercises included ACL-R to have more functional outcome, decreased knee pain and increased range of motion of knee. Core strengthening was used from first day hence early functional recovery as well $6.6 \%$ decrease in waist circumference.

\section{Female preponderance for ACL injury:}

ACL injury is one of the most common injuries in orthopedics with ACL-R among female .From 1994-2006, increasing from $32 \%$ to $42 \%$ in US (Mall et al 2014). with 4 to 6 fold increased risk of ACL tear compared with male (Myer et al 2008) variety of risk factors, including being in pre ovulatory phase of the mensural cycle, having depressed incondylar notch width, and having greater Abduction movement during impact on landing (Reinstrom et al 2008) (Wojtys et al 2002). Being a female with injury, having undergone surgery, she complaints of pain during mensural cycle.

\section{Healing based on grafting used}

ACL-soft tissue tendon grafts in corporate at 12 weeks (Rodeo et al 1993) but it takes 1-3 year for a tendon graft to ligamentize (Matsumoto et al 2006) Return to functional activity depends on the strength and function of the leg than LG biology Lee et al 2018. Lee et al 2018 have recorded recovery of quadriceps was not affected muscle strengthening by 6 months post ACL-R where as obese subjects took longer period of recovery for hamstring strength.

\section{Post Mcl Repair Rehabilitation outcome?}

Based on American medical Association on ligament injuries, this research subject MCL was graded in III Post MCL Repair, rehabilitation should aim at passive or assisted range of motion of knee from $0^{0}-90^{0}$ with two weeks post surgery to minimize arthro fibrosis along with aggressive petallo femoral mobilization, Quadriceps reactivation and frequent ankle pumps. In 6 weeks $130^{\circ}$ degree flexion of knee ,where, closed kinematic chain exercises resistance can be 
increased as tolerated by the subjects with increased in functional activities (La Prade et al 2012). ACL Reconstruction along with repair of MCL are tough currently least recommended as it seems to increase the possibility of post operative stiffness compared to the same result in terms of stability (sankar et al 2006) have in a 5 year follow-up among combined ACL \&MCL injuries followed by ACL Reconstruction was an effective treatment. Though surgically treated for ACL, MCL and Meniscus, regular adherence has yielded for her good QOL in a two year followup.

\section{Rehabilitation of Menisci Treated Surgically}

Advances in surgical techniques, to repair traumatized menisci have lead to better long term outcomes along with the rehabilitation techniques following menisci repair, decreasing the incidence of articular cartilage degeneration and earlier return to function and sport (Cavanaugh et al 2012). Meniscal repairs, were 70-90\%. Patients have recorded success with due follow ups (Belzer et al 1993) relatively stable tears rasping technique of repair is used (Uchio et al 2003) and Rehabilitation following should be customized (Cavanaugh 1991). Therapeutic exercise programs often must be modified on changes in subjective and objective findings (Cavanaugh 2003). Patient compliance with activity modification and home therapeutic exercises are vital for complete rehabilitation and a successful outcome (Cavanaugh 1991). At 4 months functional tests, single leg hop test (Daniel et al 1982).Cross over hop test (Barber et al 1990) to be performed with the goal of achieving an $85 \%$ limb symmetry score. A combination of ACL, MCL and meniscal injuries treated surgically, Rehabilitation exercises were problem specific and patient specific as supported by the above studies.

\section{Reference}

1. Hertel, H Behrend, T Cierpinski, V Musahl... - Knee Surgery, Sports 2005 ACL reconstruction using bone-patellar tendonbone press-fit fixation: 10-year clinical results May 2005, Volume 13, Issue 4, pp 248-255

2. Shelbourne, P Nitz - The American journal of sports ..., 1990 - journals.sagepub.com Accelerated rehabilitation after anterior cruciate ligament reconstruction volume: 18 issue: 3 , page(s): 292-299

3. Paulos, DC Wnorowski, CL Beck - Sports medicine, 1991 Rehabilitation Following Knee Surgery April 1991, Volume 11, Issue 4, pp 257-275

4. Wilk, MM Reinold, TR Hooks - The Orthopedic clinics of North .., 2003 europepmc.org Recent advances in the rehabilitation of isolated and combined anterior cruciate ligament injuries. [01 Jan 2003, 34(1):107-137]

5. Lephart, DM Pincivero... - The American journal ..., 1997 - journals.sagepub.com The Role of Proprioception in the Management and Rehabilitation of Athletic Injuries. volume: 25 issue: 1, page(s): 130-137 Issue published: January 1, 1997

6. Kegler, C Escoffery, I Alcantara... International..., 2008Mijbnpa.biomedcentral.com A qualitative examination of home and neighborhood environments for obesity prevention in rural adults. International Journal of Behavioral Nutrition and Physical Activity volume 5, Article number: 65 (2008)

7. Griffith CJ, Wijdicks CA, LaPrade RF, Armitage BM, Johansen S, Engebretsen L. Force measure- ments on the posterior oblique ligament and superficial medial collateral ligament proximal and distal divisions to applied loads. Am J Sports Med. 2009;37:140-148. http://dx.doi.

8. Wijdicks CA, Griffith CJ, Johansen S, Engebretsen L, La Prade RF. Injuries to the medial collateral ligament and associated medial 
structures of the knee. J Bone Joint Surg Am. 2010;92:1266-1280.

http://dx.doi.org/10.2106/ JBJS.I.01229

9. Grant JA, Tannenbaum E, Miller BS, et al. Treatment of combined complete tears of the anterior cruciate and medial collateral ligaments. Arthroscopy 2012;28:110-22.

10. Wirth CJ. The meniscus: structure, morphology and function. Knee. 1996;3:5758

11. Karahan M, Kocaoglu B, et al. Effect of partial medial meniscectomy on the proprioceptive function of the knee. Arch Orthop Trauma Surg. 2010;130(3):427-431. doi: 10.1007/s00402-009-1018-2.

12. Warren RF, Marshall J. Injuries of the anterior cruciate ligament and medial collateral ligament of the knee. Clin Orthop. 1978;136:191.

13. Howell GED. Clinical presentation of the knee. In: Bulstrode CJK, Buckwalter J, Carr A, Marsh L, Fairbank J, Wilson-MacDonald J, Bouden G, editors. Oxford textbook of orthopedics and trauma. New York: Oxford University Press; 2002. pp. 1108-1113.

14. Malempati, DO; John Jurjans, PT, ATC, SCS; Brian Noehren, PT, PhD; Mary L. Ireland, MD; Darren L. Johnson, MD Current Rehabilitation Concepts for Anterior Cruciate Ligament Surgery in Athletes Orthopedics. 2015;38(11):689-696, November 11, 2015

15. Malone T. Anterior cruciate ligament rehabilitation. In: Johnson DL, Mair SD, eds. Clinical Sports Medicine. Philadelphia, PA: Elsevier; 2006:655-656.

16. Wilk, Kevin E.a | Keirns, Michael A.a | Andrews, James R.a; | Clancy, William G.a; Arrigo, Christopher A. | Erber, Donna J.a; Journal: Isokinetics and Exercise Science, Anterior Cruciate Ligament Reconstruction Rehabilitation: A Six-Month Followup of Isokinetic Testing in Recreational Athletes. vol. 1, no. 1, pp. 36-43, 1991 Accepted October 1990 | Published: 1 January 1991.
17. Shelbourne KD, Nitz P. Accelerated rehabilitation after anterior cruciate ligament reconstruction. Am J Sports Med. 1990: 18(3):292-299.

18. Shelbourne KD, Klotz C. What I have learned about the ACL: utilizing a progressive rehabilitation scheme to achieve total knee symmetry after anterior cruciate ligament reconstruction. J Orthop Sci. 2006; 11(3):318-325.

19. Meunier A, Odensten M, Good L. Long-term results after primary repair or non-surgical treatment of anterior cruciate ligament rupture: a randomized study with a 15-year follow-up. Scand J Med Sci Sports. 2007 Jun;17(3):230-7.

20. Fithian DC, Paxton EW, Stone ML, Luetzow WF, Csintalan RP, Phelan D, Daniel DM. Prospective trial of a treatment algorithm for the management of the anterior cruciate ligament-injured knee. Am J Sports Med. 2005 Mar;33(3):335-46.

21. McDaniel, JTB Dameron - The Journal of bone and joint ..., 1980 - europepmc.org. Untreated ruptures of the anterior cruciate ligament.A follow-up study.The Journal of Bone and Joint Surgery. American Volume [01 Jul 1980, 62(5):696-705]

22. Shi, J Li, H Zhai, H Wang, H Meng... - ... rehabilitation, 2012 - content.iospress.com. Specialized core stability exercise: A neglected component of anterior cruciate ligament rehabilitation programs .Journal of Back and Musculoskeletal Rehabilitation, vol. 25, no. 4, pp. 291-297, 2012 Published: 28 November 2012

23. Panchal Priyanka, Bedekar Nilima, Sancheti Parag, First Published December 1, 2017 Effects of Lumbar Core Stability Exercise Programme on Knee Pain, Range of Motion, and Function Post Anterior Cruciate Ligament Reconstruction Volume 23 Issue 1, December 2017

24. Mall NA, Chalmers PN, Moric M, Tanaka MJ, Cole BJ, Bach BR Jr2, Paletta GA Jr4. 
Incidence and trends of anterior cruciate ligament reconstruction in the United States. 2014 Oct;42(10):2363-70. doi: 10.1177/0363546514542796. Epub 2014 Aug 1.

25. Myer GD1, Paterno MV, Ford KR, Hewett TE. 2008. Neuromuscular training techniques to target deficits before return to sport after anterior cruciate ligament reconstruction . Jun;42(6):394-412.

26. Renstrom P, Ljungqvist A, 11on page 1on page 1 on page 1 on page 1 (lee)Arendt $\mathrm{E}$, Beynnon B, Fukubayashi T, Garrett W, Georgoulis T, Hewett TE, Johnson R, Krosshaug T, Mandelbaum B, Micheli L, Myklebust G, Roos E, Roos H, Schamasch P, Shultz S, Werner S, Wojtys E, Engebretsen L.Non-contact ACL injuries in female athletes: an International Olympic Committee current concepts statement. Br J Sports Med 2008;42:394-412

27. Wojtys EM, Huston L, Boynton MD,et al. The effect of menstrual cycle on anterior cruciate ligament in women as determined by hormone levels. Am J Sports Med 2002;30:182-8.

28. Rodeo SA, Arnoczky SP, Torzilli PA et al (1993) Tendonhealing in a bone tunnel. A biomechanical and histological study in the dog. J Bone Joint Surg Am 75(12):17951803

29. Matsumoto A, et al. A comparison of bonepatellar tendon-bone and bone-hamstring tendon-bone autografts for anterior cruciate ligament reconstruction. Am J Sports Med. 2006;34(2):213-219.

doi: 10.1177/0363546505279919.

30. Lee, Adam Margalit, Afam Nduaguba2, Melissa A Gunderson2 and Lawrence Wells. Obesity and recovery of muscle strength after anterior cruciate ligament reconstruction in pediatric patients. Journal of Orthopaedic Surgery: 2018 - 26(3) 1-6.
31. Laprade RF, Wijdicks CA. Surgical technique: development of an anatomic medial knee reconstruction. Clin Orthop Relat Res 2012;470:806-14.

32. Sankar WN, et al. Combined anterior cruciate ligament and medial collateral ligament injuries in adolescents. J Pediatr Orthop. 2006;26(6):733-6.

33. Cavanaugh \& Sarah E. Killian. Rehabilitation following meniscal repair. Curr Rev Musculoskelet Med (2012) 5:46-58

34. Cavanaugh JT. Rehabilitation following meniscal surgery. In: Engle RP, editor. Knee Ligament Rehabilitation. New York: Churchill Livingston; 1991. p. 59-69.

35. Belzer J, Cannon W. Meniscal tears: treatment in the stable and unstable knee. Journal of the American Academy of Orthopedic Surgeons. 1993;1(1):41-7.

36. Uchio Y, Ochi M, Adachi N, et al. Results of rasping of meniscal tears with and without anterior cruciate ligament injury as evaluated by second-look arthroscopy. Arthroscopy. 2003;19(5):463-9.

37. Cavanaugh JT. Rehabilitation for non operative and operative management of knee injuries. In: Callaghan J, Simonian P, Wickiewicz $\mathrm{T}$, editors. The adult knee. Lipponcott: Wilkens Publishers; 2003. p. 380-430.

38. Barber SD, Noyes FR, Mangine RE, et al. Quantitative assessment of functional limitations in normal and anterior cruciate ligament deficient knees. Clin Orthop. 1990;255:204-14. 